\title{
Co-treatment with hepatocyte growth factor and TGF- $\beta 1$ enhances migration of HaCaT cells through NADPH oxidase-dependent ROS generation
}

\author{
Hyun-Ja Nam ${ }^{1,2}$, Yun-Yeon Park ${ }^{1,2}$, Gyesoon Yoon ${ }^{1,2}$, \\ Hyeseong Cho ${ }^{1,2}$ and Jae-Ho Lee ${ }^{1,2,3}$ \\ ${ }^{1}$ Department of Biochemistry and Molecular Biology \\ Ajou University School of Medicine \\ ${ }^{2}$ Department of Molecular Science and Technology \\ Graduate School of Ajou University \\ Suwon 443-721, Korea \\ ${ }^{3}$ Corresponding author: Tel, 82-31-219-5053; \\ Fax, 82-31-219-5059; E-mail, jhlee64@ ajou.ac.kr \\ DOI 10.3858/emm.2010.42.4.026
}

Accepted 2 February 2010

Available Online 22 February 2010

Abbreviations: DCF-DA, 2',7'-dichlorofluorescein diacetate; NOX, NADPH oxidase; ROS, reactive oxygen species

\begin{abstract}
Wound healing requires re-epithelialization from the wound margin through keratinocyte proliferation and migration, and some growth factors are known to influence this process. In the present study, we found that the co-treatment with hapatocyte growth factor (HGF) and TGF- $\beta 1$ resulted in enhanced migration of $\mathrm{HaCaT}$ cells compared with either growth factor alone, and that $\mathrm{N}$-acetylcysteine, an antioxidant agent, was the most effective among several inhibitors tested, suggesting the involvement of reactive oxygen species (ROS). Fluorescence-activated cell sorter analysis using 2',7'-dichlorofluorescein diacetate (DCF-DA) dye showed an early $(30 \mathrm{~min})$ as well as a late $(24 \mathrm{~h})$ increase of ROS after scratch, and the increase was more prominent with the growth factor treatment. Diphenyliodonium (DPI), a potent inhibitor of NADPH oxidase, abolished the increase of ROS at $30 \mathrm{~min}$, followed by the inhibition of migration, but not the late time event. More precisely, gene knockdown by shRNA for either Nox-1 or Nox-4 isozyme of gp91phox subunit of NADPH oxidase abolished both the early time ROS production and migration. However, HaCaT cell migration was not enhanced by treatment with $\mathrm{H}_{2} \mathrm{O}_{2}$. Collectively, co-treatment with HGF and TGF- $\beta 1$ enhances keratinocyte migration, accompanied with ROS generation through NADPH oxidase, involving Nox-1 and Nox-4 isozymes.
\end{abstract}

Keywords: cell movement; hepatocyte growth factor; keratinocytes; NADPH oxidase; reactive oxygen species; transforming growth factor $\beta 1$

\section{Introduction}

Wound healing after injury is a complex process encompassing many cellular and biochemical events to restore tissue integrity. Several growth factors, synthesized mainly by activated macrophages are released from wound region during these phases in paracrine or autocrine manner (Singer and Clark, 1999). It is well known that released growth factors and cytokines control tissue repair process: Exogenous addition of growth factors such as PDGF, fibroblast growth factor (FGF), epidermal growth factor (EGF), TGF- $\alpha$ and TGF- $\beta 1$ to animal wounds usually accelerates tissue repair rate by enhancing granulation tissue formation or keratinocyte migration (Robinson, 1993; Steed, 1998; Carter, 2003).

Hepatocyte growth factor (HGF) is secreted mainly by mesenchymal cells such as fibroblasts and leads to motility, migration, and morphological changes in several cell types (Zarnegar and Michalopoulos, 1995). HGF also plays important roles in wound healing process, in that it primes neutrophils, facilitates migration of endothelial cells and epithelial cells, and enhances matrix synthesis and matrix deposition (Conway et al., 2006). TGF- $\beta 1$ is a member of large family of growth factors involved in regulation of cellular growth and differentiation (Kingsley, 1994; Taipale et al., 1998). Among many molecules known to influence wound healing, TGF- $\beta 1$ has the broadest spectrum of actions, affecting all cell types that are involved in all stages of wound healing. Both positive and negative effects of TGF- $\beta 1$ on wound healing have been reported (Wang et al., 2006). Although HGF and TGF- $\beta 1$ usually acts antagonistically in many systems, the reports on the positive effect of TGF- $\beta 1$ in skin wound healing led us to assume that HGF and TGF- $\beta 1$ might not act antagonistically on keratinocyte migration, and to compare the effect of co-treatment with HGF and TGF- $\beta 1$ with either growth factor alone in keratinocyte migration.

Stimulation of the cells with growth factors leads 
to the activation of diverse intracellular signaling molecules. It is also widely recognized that cells produce intracellular reactive oxygen species (ROS) when stimulated by growth factors. Production of ROS regulates signaling pathway and gene expression involving cell proliferation, survival, apoptosis or inflammation (Finkel, 1998; Gamaley and Klyubin, 1999; Finkel, 2000; Finkel and Holbrook, 2000). Regarding the source of ROS after activation by growth factor, NADPH oxidase in plasma membrane is one of the primary candidates along with xanthine oxidase, cytochrome p450, cyclooxygenase (COX), lipoxygenase (LO) existing inside the cell as well as mitochondria (Logan, 2006).

In this study, we found that the co-treatment with HGF and TGF- $\beta 1$ resulted in enhanced migration of human keratinocyte HaCaT cells, compared with either growth factor alone. Moreover, we found that the enhanced cell migration was found to be dependent on ROS generation mediated by NADPH oxidases. Our data provide potential implication of the combined use of HGF and TGF- $\beta 1$ to enhance wound healing and the understanding of the importance of NADPH-generated ROS in this process.

\section{Results}

\section{Co-treatment with HGF and TGF- $\beta 1$ enhances HaCaT cell migration}

To gain insight into the function of HGF and/or TGF- $\beta 1$ in keratinocyte migration, we performed scratch wound assay using $\mathrm{HaCaT}$ human keratinocytes with a micropipette tip in the presence or absence of growth factors. Whereas HGF induced narrowing of the scratch wound, TGF- $\beta 1$ showed less effect. Interestingly, we found that co-treatment with HGF and TGF- $\beta 1$ resulted in enhanced cell migration compared with either growth factor alone (Figures $1 \mathrm{~A}$ and $1 \mathrm{~B}$ ). Since growth factors such as HGF promote cell proliferation, it might be possible that the enhanced narrowing of the wound was due to their effects on cell proliferation. However, whereas cell proliferation was increased in $10 \%$ serum condition compared to $0.5 \%$ serum condition, cell migration measured by wound healing assay was not the case. In addition, co-treatment of the wounded cells with HGF and TGF- $\beta 1$ resulted in less cell proliferation than with HGF alone (Figure 1C), suggesting that just the increase of cell proliferation could not induce the observed enhancement of wound healing. We further addressed the effect of the growth factors on cell migration by using trans-well chamber, and found that co-treatment with both growth factors again significantly induced cell migration compared with either growth factor alone (Figure 1D), thus confirming that the increase of cell migration most probably was the cause of enhanced wound healing by co-treatment with HGF and TGF- $\beta 1$. Interestingly, while HGF induced wound healing better than TGF- $\beta 1$, TGF- $\beta 1$ induced far more trans-well migration than HGF (Figures $1 \mathrm{~B}$ and 1D). It might be related with the difference of two assays: While the former uses attached cells, the latter uses single cells.

\section{ROS generation is necessary for the enhancement of cell migration by combined growth factor treatment}

To verify the signal transduction pathway responsible for the increase of re-epithelialization, wellknown inhibitors of various signaling pathways were pre-treated before the wound generation and cytokine treatment. Among the inhibitors tested, $\mathrm{N}$-acetylcysteine (NAC), an antioxidant, along with PD98059 were the most effective ones in inhibiting re-epithelialization (Supplemental Data Figure S1), suggesting the involvement of ROS and ERK signaling in this process. Since ROS is widely recognized as one of the diverse intracellular signaling molecules when stimulated by growth factors, we next performed ROS analysis by using FACS and confocal microscope after staining with DCF-DA dye. FACS analysis revealed that ROS level slightly but statistically significantly increased after the scratch at both early (30 min) and late (20 h) time points when treated with both HGF and TGF- $\beta 1$ at both $30 \mathrm{~min}$ and at $24 \mathrm{~h}$ compared with those without growth factor treatment (Figure 2A). Observation of DCF-DA fluorescence by confocal microscopy also revealed the increase of ROS by growth factor treatment. Notably, the increase of ROS was evident mainly at the margins of wound, suggesting that the scratch-induced damage to the cells was the source of initial signaling for ROS generation (Figure 3B, upper panels). To address whether the ROS generation is essential in HaCaT cell migration, $\mathrm{N}$-acetylcysteine, an antioxidant, was treated prior to the application of growth factors and wound generation. Indeed, N-acetylcyteine significantly abolished cell migration in a dose-dependent manner (Figure 2B), suggesting the strong involvement of ROS in this process.

\section{Diphenyliodonium significantly inhibits the increase of ROS at early time point, but not at late time point, followed by inhibition of cell migration}

Originally, ROS were recognized as an instrument 
A

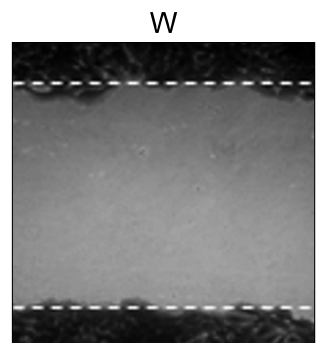

WH

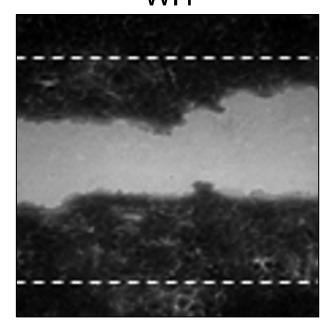

WT

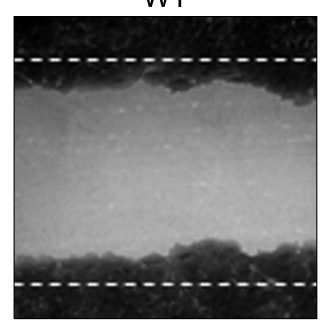

WTH

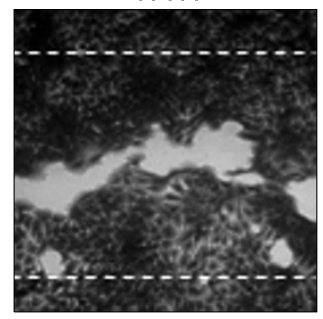

B

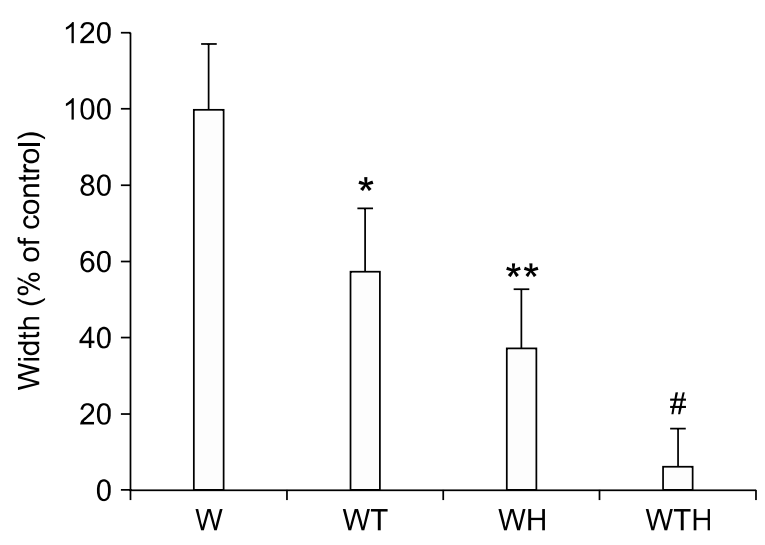

D

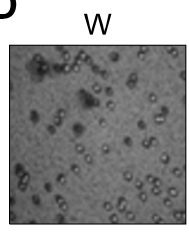

WT

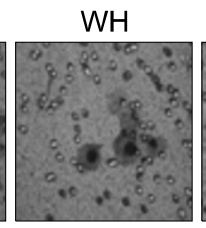

WTH

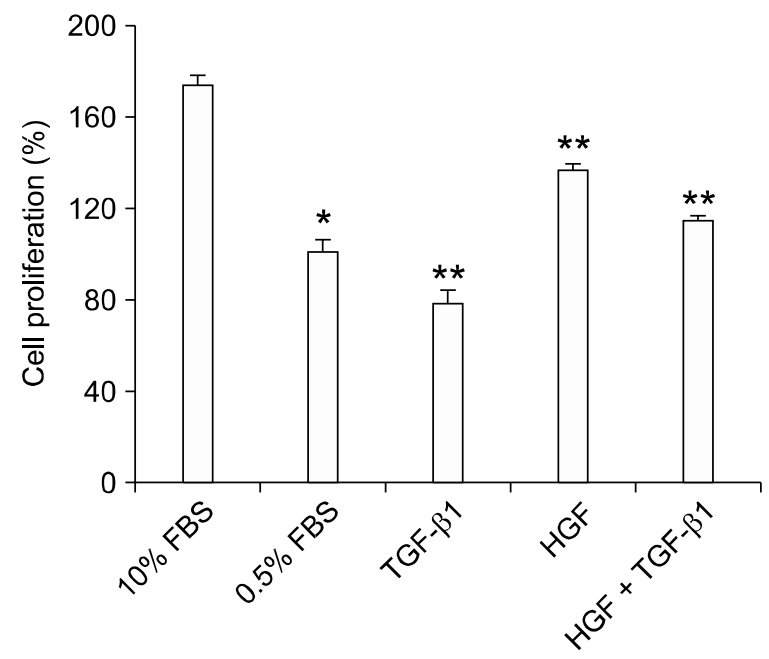

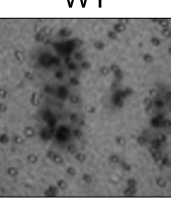

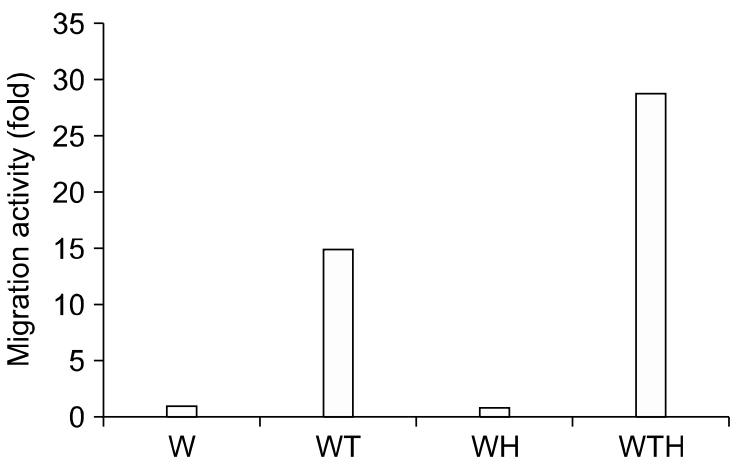

Figure 1. Co-treatment with HGF and TGF- $\beta 1$ enhanced HaCaT cell migration. (A) Scratch wound assay. HaCaT cells were seeded in 24-well plates. After $24 \mathrm{~h}$, cells were scratched using a micropipette tip, and growth factors were added as indicated. After incubation for $24 \mathrm{~h}$, the indicated wells were stained with crystal violet. Representative pictures from three independent experiments are shown. (B) The width of the wound was measured by using ocular lens with ruler. Data are presented as mean \pm SD of three independent experiments. W: No treatment, WT: TGF- $\beta 12$ ng/ml, WH: HGF 30 units/ml, WTH: HGF 30 units/ml + TGF- $\beta 12 \mathrm{ng} / \mathrm{ml}\left(n=25,{ }^{*}\right.$ and ${ }^{* *} ; P<0.01$ compared to control, \#; $P<0.01$ between WH and WTH; student's $t$-test). (C) Cell proliferation assay. HaCaT cells were seeded in 96-well plates before the respective growth factors were added. After $24 \mathrm{~h}$ of the treatment with growth factors as indicated, MTT assay was performed. $\left(n=6,{ }^{*}: P<0.01\right.$ compared to $10 \%$ FBS group, ${ }^{* *}: P<0.01$ compared to $0.5 \%$ FBS group by student's $t$-test). Data are presented as mean \pm SD of two independent experiments. (D) Cell migration assay. HaCaT cells were seeded at a density of $1.0 \times 10^{4} \mathrm{cells} /$ well in upper chamber prior to the treatment with cytokines indicated. After $24 \mathrm{~h}$ of the treatment with cytokines, cells were fixed with acetone: methanol (1:1), and stained with crystal violet. Representative pictures from two independent experiments are shown.

for mammalian host defense, and early works led to the characterization of the respiratory burst of neutrophils and finally the NADPH oxidase complex, which is now recognized as a primary source of ROS. To address whether the origin of ROS production in our system was NADPH oxidase complex, we pre-treated HaCaT cells with diphenyliodonium (diphenyliodonium; $5 \mu \mathrm{M}$ ), an NADPH oxidase inhibitor, before growth factor treatment that was followed by scratch. Interestingly, pre-treatment of the cells with diphenyliodonium resulted in a complete inhibition of early time point 
A

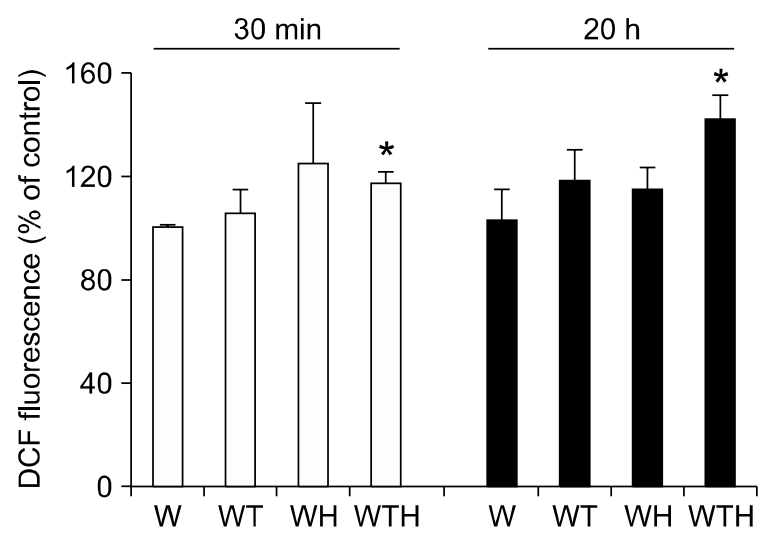

B

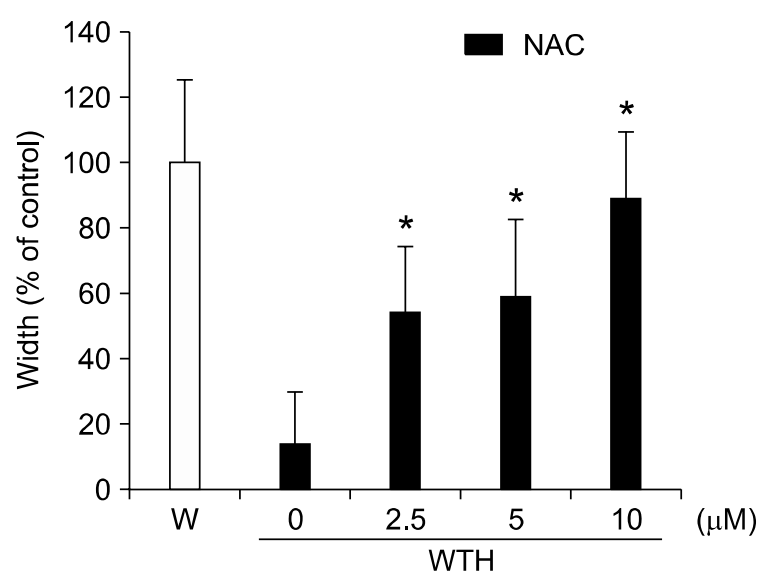

Figure 2. ROS induction at early and late time points following scratch wound was enhanced by combined growth factor treatment. (A) Enhanced ROS production by co-treatment with HGF and TGF- $\beta 1$. HaCaT cells were scratched using a comb and cytokines were treated as indicated. After incubating for $30 \mathrm{~min}$ or $20 \mathrm{~h}$, cells were incubated for $10 \mathrm{~min}$ with DCF-DA, and then harvested for the FACS analysis. Data are presented as mean \pm SD of three independent experiments ( ${ }^{*} ; P<0.01$ compared to that without cytokine treatment by student's $t$-test). (B) $\mathrm{N}$-acetylcyteine (NAC) could block the re-epithelialization of $\mathrm{HaCaT}$ cells induced by co-treatment with HGF and TGF- $\beta 1$. HaCaT cells were pre-treated with or without indicated concentrations of NAC $(2.5 \mu \mathrm{M}, 5 \mu \mathrm{M}, 10 \mu \mathrm{M})$ for 30 min before scratched and growth factors were added as indicated. Data are presented as mean \pm SD of three independent experiments.

ROS production in response to scratch wound itself as well as to the combined growth factor stimulation (Figure 3A, left, arrowheads). On the other hand, ROS generation at $20 \mathrm{~h}$ was not abolished by diphenyliodonium treatment (Figure $3 \mathrm{~A}$, right), which was the case even with re-application of diphenyliodonium at $18 \mathrm{~h}$ post-scratch (data not shown), indicating that the failure of diphenyliodonium to inhibit the late-time point ROS generation was not due to possible instability of the inhibitor in culture medium. Observation of DCF fluorescence by confocal microscopy confirmed the inhibition of ROS generation by diphenyliodonium in response to scratch wound itself as well as to the combined growth factor stimulation (Figure 3B, lower panels).

We then asked whether diphenyliodonium treatment of the cells could inhibit HaCaT cell migration. Indeed, diphenyliodonium partially, but significantly abolished wound healing in a concentration-dependent manner (Figure 3C). Therefore, ROS generation by NADPH oxidase seemed to be necessary for the migration of HaCaT keratinocytes after the treatment with HGF and TGF- $\beta 1$.

\section{Knockdown of either Nox-1 or Nox-4 isozyme of p91 ${ }^{\text {phox }}$ subunit of NADPH oxidase inhibits ROS production and $\mathrm{HaCaT}$ cell migration}

We next tried to further confirm the involvement of NADPH oxidase complex by using molecular bio- logical approach. NADPH oxidase complex consists of various subunit proteins, including $\mathrm{p} 91^{\text {phox }}$ isozymes. Since Nox-1 and Nox-4 were reported to be present in $\mathrm{HaCaT}$ cells (Chamulitrat et al., 2004), we tested whether knock-down of Nox-1 or Nox-4 using specific shRNAs in $\mathrm{HaCaT}$ cells could abolish the ROS generation. Indeed, transfection of either shRNA for Nox-1 or Nox-4, but not control shRNA, almost completely abolished ROS production in response to scratch wound itself as well as to the combined growth factor stimulation (Figure $4 \mathrm{~A})$, confirming the involvement of NADPH oxidase complex in wound-induced as well as growth factor-induced ROS generation.

In line with the inhibition of $\mathrm{HaCaT}$ migration by diphenyliodonium, we next addressed whether Nox-1 or Nox-4 depletion also inhibited the wound healing. As shown in Figure 4B, knock-down of either Nox-1 or Nox-4 effectively inhibited the wound healing by co-treatment with HGF and TGF- $\beta 1$. These results demonstrated that NADPH oxidase-mediated ROS production is essential for promotion of $\mathrm{HaCaT}$ cell migration, and both Nox-1 and Nox-4 are necessary I this process.

\section{PI3K pathway is involved in re-epithelialization process, but not in ROS generation}

Non-phagocytic cells produce superoxide anions in response to growth factors including PDGF and EGF (Sundaresan et al., 1995; Bae et al., 1997). 
A
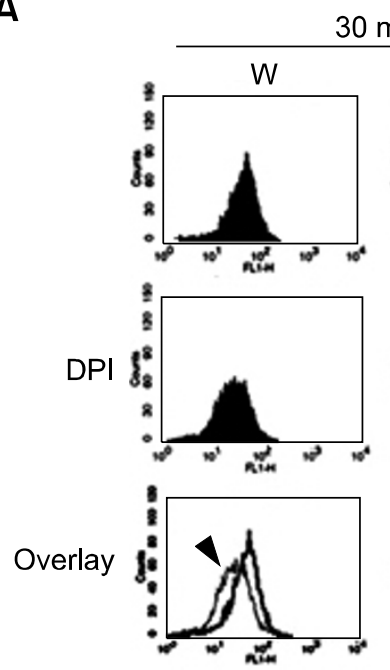

B

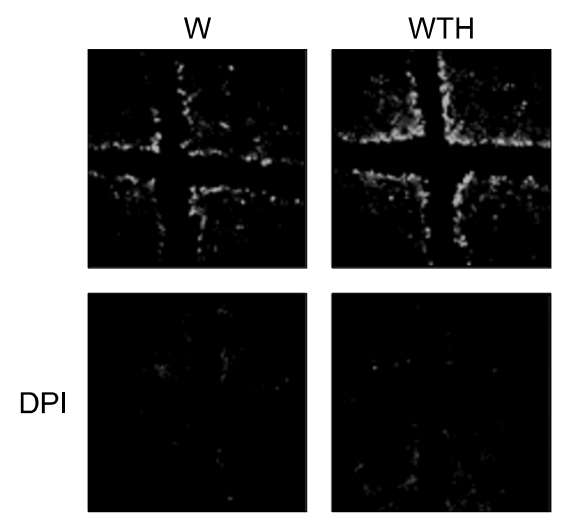

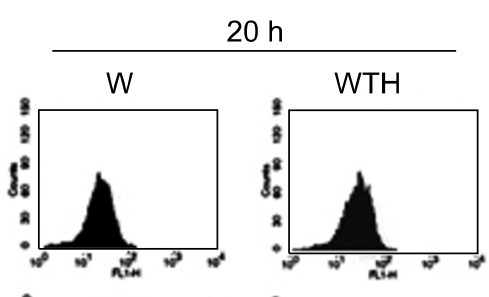
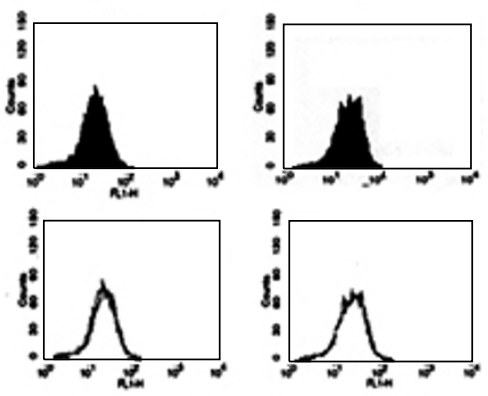

C

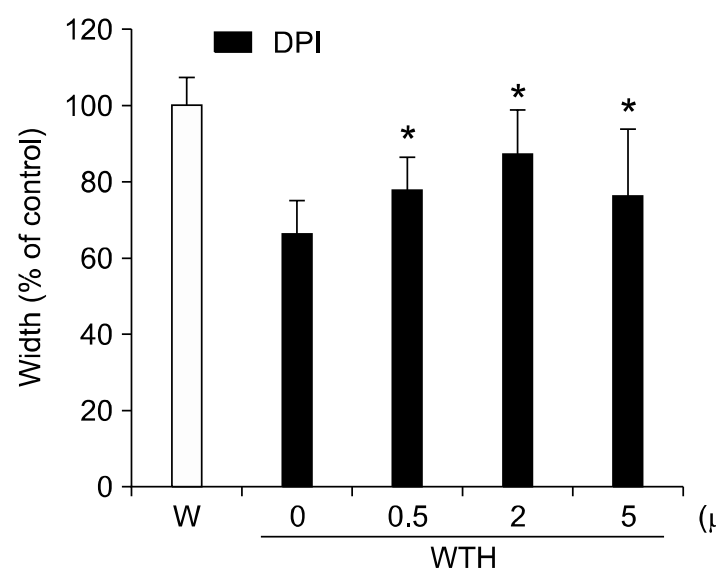

$(\mu \mathrm{M})$

Figure 3. Diphenyliodonium (DPI) inhibited the increase of ROS significantly at early time point, but not at late time point, followed by inhibition of HaCaT cell migration. (A) and (B) diphenyliodonium inhibited significantly the increase of ROS at early time point. (A) HaCaT cells were pretreated with diphenyliodonium $(5 \mu \mathrm{M})$ for $1 \mathrm{~h}$ before scratching, and growth factors for 30 min were added as indicated. Representative images of FACS analysis of three independent experiments are presented. Arrowheads denote FACS profiles of diphenyliodonium-treated samples. (B) Diphenyliodonium as well as growth factors were applied as described in (A). After incubation with DCF-DA, cells were observed under a confocal microscope. Representative images from two independent experiments are presented. (C) Migration of HaCaT cells was inhibited by diphenyliodonium treatment. HaCaT cells were pretreated for $1 \mathrm{~h}$ with indicated concentrations of diphenyliodonium before scratching and growth factors were applied as indicated. Data are presented as mean $\pm \mathrm{SD}$ of two independent experiments $\left({ }^{*} ; P<0.05\right.$ compared to that without diphenyliodonium by student's $t$-test).

Especially, ROS production in PDGF-stimulated cells has been shown to be mediated by sequential activation of phosphatidylinositol 3- kinase (PI3K), $\beta P i x$, and Rac1, which then binds to Nox1 to stimulate its NADPH oxidase activity (Bae et al., 2000; Park et al., 2004). Therefore, we next investigated the involvement of PI3K pathway in the ROS generation and wound healing process. Interestingly, whereas $\mathrm{HaCaT}$ cell migration was inhibited in dose-dependent manners by either wortmannin or LY294002 (Figures 5A and 5B), wortmannin or LY294002 did not abolish the increase of ROS at both early (30 min; Figures $5 \mathrm{C}$ and 5D) and late time points $(20 \mathrm{~h}$; data not shown). These results suggest that PI3K pathway is indeed involved in $\mathrm{HaCaT}$ keratinocyte migration by growth factor co-treatment, but not through affecting ROS production. In fact, when we treated various signaling inhibitors prior to the addition of growth factors and wound generation, we observed that several different inhibitors could abolish the HaCaT cell migration (Supplemental Data Figure S1), which suggests that keratinocyte migration is a rather complex process which requires the har- 
A
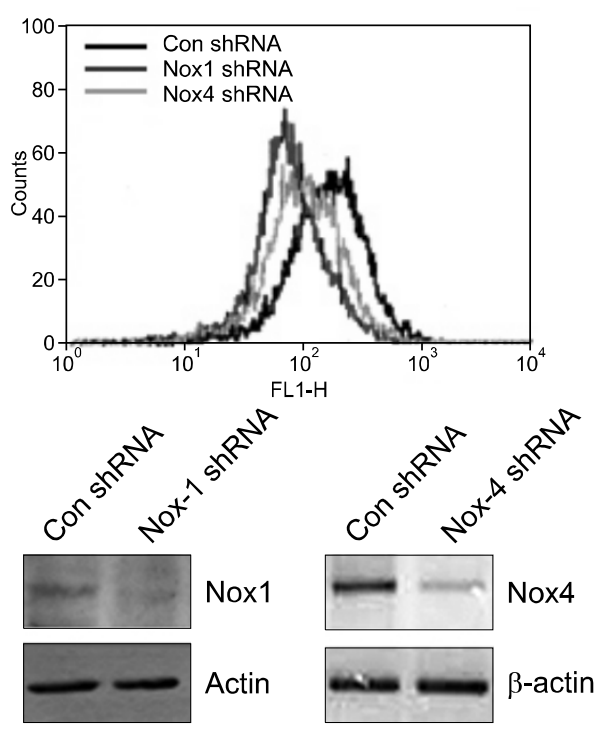

B

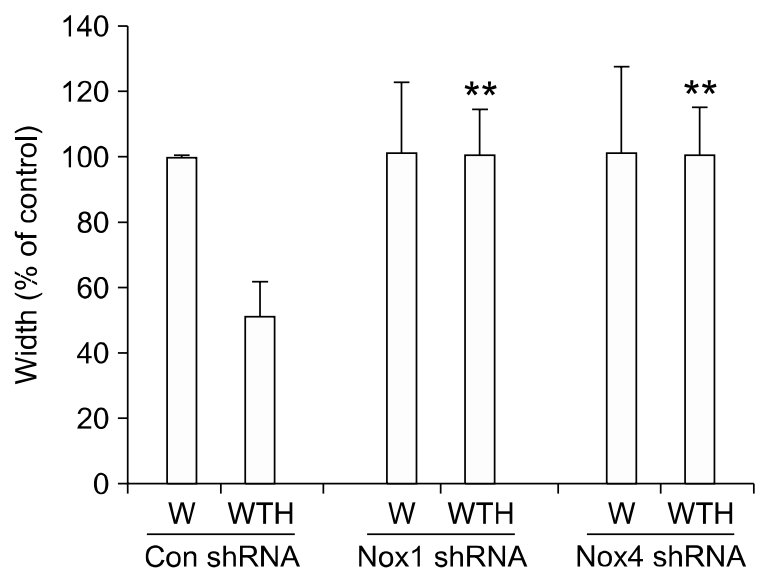

monious involvement of various intracellular signaling systems.

\section{$\mathrm{H}_{2} \mathrm{O}_{2}$ is not sufficient for inducing HaCaT cell migration}

We found that ROS production by co-treatment of $\mathrm{HaCaT}$ cells with HGF and TGF- $\beta 1$ was necessary for wound migration (Figure 3). Therefore, to address whether ROS generation is sufficient for migration, scratch wound assay was performed in the presence of different concentrations of $\mathrm{H}_{2} \mathrm{O}_{2}$. As shown in Figure 6A, HaCaT cell migration was not enhanced by $\mathrm{H}_{2} \mathrm{O}_{2}$ within a concentration range tested, indicating that the increase of ROS production such as $\mathrm{H}_{2} \mathrm{O}_{2}$ is necessary but not sufficient for migration. However, there is a possibility that the cytotoxic effect of $\mathrm{H}_{2} \mathrm{O}_{2}$ at high concen-

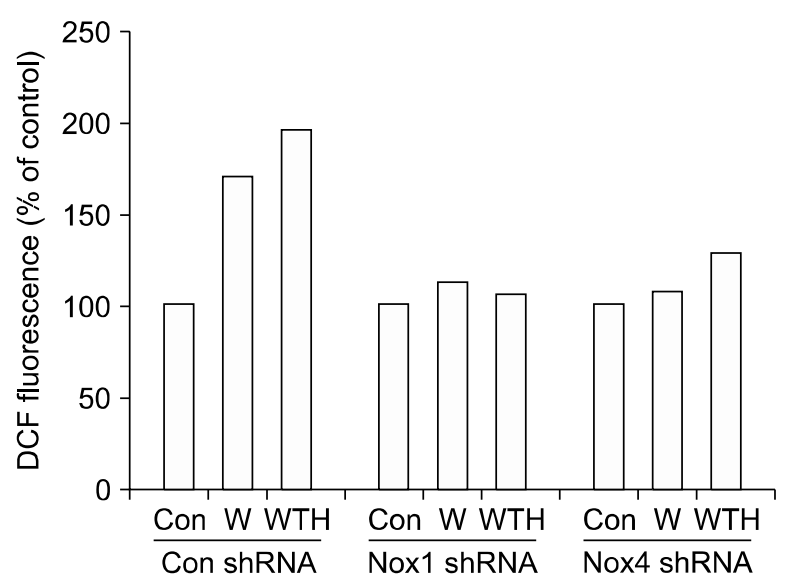

Figure 4. Knock-down of Nox-1 or Nox-4 confirmed the involvement of NADPH oxidase in ROS generation after wound. (A) Depletion of either Nox-1 or Nox-4 significantly inhibited ROS production. After indicated plasmids were electroporated cells were scratched and growth factors were added as indicated. Thirty min later, cells were harvested and subjected to FACS analysis after DCF-DA staining. Representative data from two independent experiments are shown (right panel), and the extent of knock-down of Nox-1 and Nox-4 was measured by western blotting and RT-PCR, respectively (left lower panel). Representative FACS profiles are overlaid to reveal the differences between samples. Only the differences between samples with both wound and growth factor treatment were shown (left upper panel). Con shRNA: pSuper plasmid itselfplasmid transfected cells. (B) HaCaT cell migration was inhibited by depletion of either Nox-1 or Nox-4. Cells harboring indicated shRNAs were subjected to scratch wound assay. Data are presented as mean \pm SD of two independent experiments (**; $P<0.01$ compared to pSuper-transfected cells by student's t-test).

tration range (Figure 6B) would interfere with the possible wound healing effect of $\mathrm{H}_{2} \mathrm{O}_{2}$ at these concentration ranges.

\section{Discussion}

ROS, such as superoxide anions and hydrogen peroxide $\left(\mathrm{H}_{2} \mathrm{O}_{2}\right)$, is produced in mammalian cells in response to the activation of various cell surface receptors, and contribute to intracellular signaling and regulation of various biological activities (Finkel, 2000; Lambeth et al., 2000). Receptor-mediated ROS production has been extensively studied in phagocytic cells. The enzyme NADPH oxidase of such cells is composed of at least five protein components, namely two transmembrane flavocytochrome b components 
A

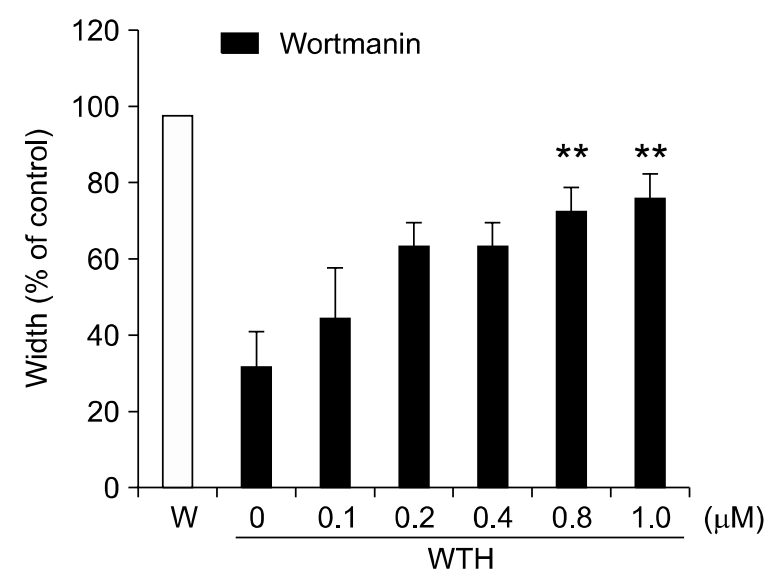

C

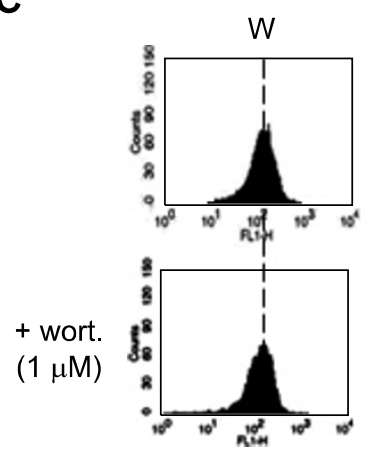

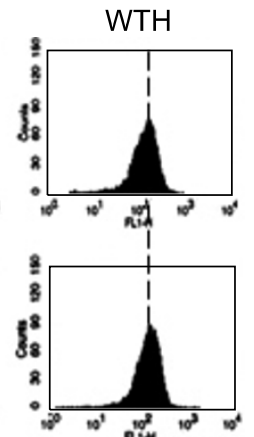

B

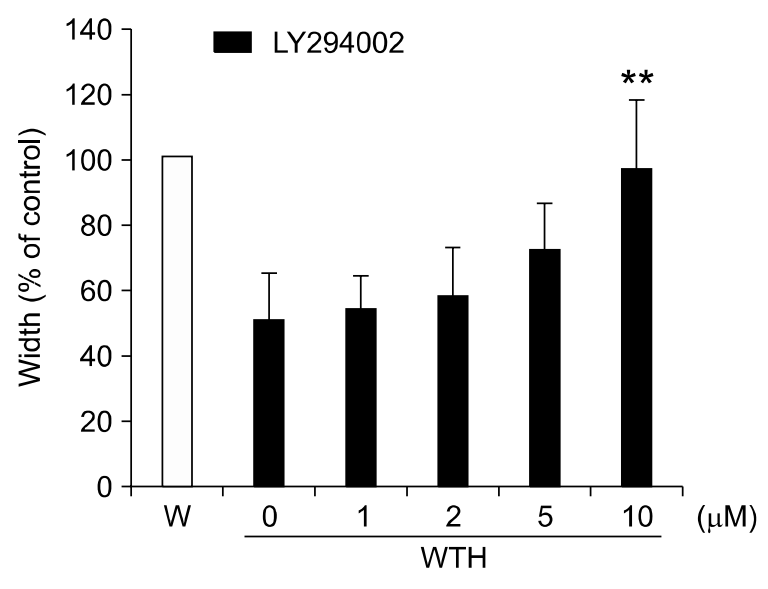

D

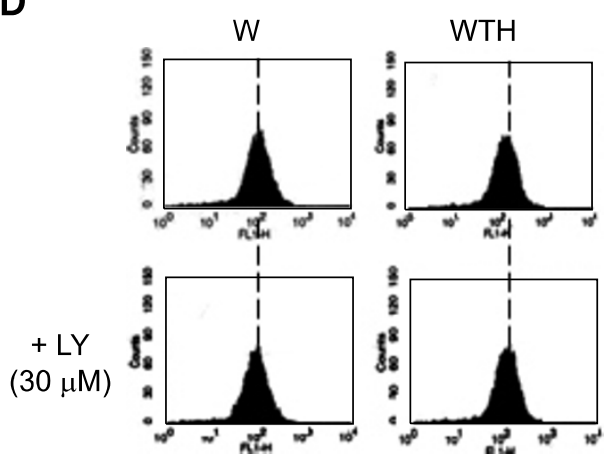

Figure 5. PI3K pathway was involved in cell migration, but not in ROS generation. (A) and (B) HaCaT cell migration was inhibited by PI3K inhibitors. $\mathrm{HaCaT}$ cells were pretreated for $1 \mathrm{~h}$ with wortmannin (A) or LY294002 (B) at the indicated concentrations before scratching. Growth factors were added as indicated just after the scratch. Data are presented as mean $\pm \mathrm{SD}$ of two independent experiments. ${ }^{* *} ; P<0.01$ compared to that without inhibitors by student's $t$-test). (C) and (D) Wortmannin (1 $\mu \mathrm{M})$ and LY294002 (30 $\mu \mathrm{M})$ could not abolish the increase of ROS. HaCaT cells were prepared as indicated (A). Then, cells were incubated for 10 min with DCF-DA harvested for FACS analysis. Peak fluorescence intensity was measured for each sample, and a representative data from two independent experiments are shown. Vertical dashed line was drawn to help compare the location of two peaks.

$\left(\mathrm{gp} 91^{\text {phox }}\right.$ and $\left.\mathrm{p} 22^{\text {phox }}\right)$ and three cytosolic components $\left(\mathrm{p} 47^{\mathrm{phox}}, \mathrm{p} 67^{\text {phox }}\right.$, and $\left.\mathrm{p} 40^{\text {phox }}\right)$ (Babior, 1999). The exposure of resting phagocytic cells to an appropriate stimulus results in extensive phosphorylation of the cytosolic components of NADPH-oxidase and their association with the transmembrane flavocytochrome b components (Ago et al., 1999; Cross et al., 1999). The assembled oxidase complex catalyzes the transfer of an electron to $\mathrm{O}_{2}$ to yield superoxide anion and $\mathrm{H}_{2} \mathrm{O}_{2}$. Several homologs (Nox-1, Nox-3, Nox-4, Nox-5, Duox1, and Duox2) of gp9 $1^{\text {phox }}$ (Nox-2) have been identified in various non-phagocytic cells (Cheng et al., 2001). Based on the effect of Nox-1 antisense RNA in smooth muscle cells, Nox-1 has been implicated in PDGF-induced ROS production (Lassegue et al., 2001). Nox-4 has also been reported to play a central role in LPS-induced pro-inflammatory responses of endothelial cells in an ROS-dependent manner (Park et al., 2006), and is shown to be expressed in melanoma cells as well as normal human epidermal melanocytes (Brar et al., 2002). To the best of our knowledge, this is the first report showing the involvement of Nox-1 and Nox-4 in keratinocyte migration.

Although ROS generation was focused as one of the responsible signaling pathways in keratinocyte migration, it seems that numerous different major signaling pathways are necessary for the completion of this process: (i) Exogenous addition of $\mathrm{H}_{2} \mathrm{O}_{2}$ was not sufficient to induce cell migration (Figure 6), (ii) the inhibition of PI3K with two different inhibitors also prevented $\mathrm{HaCaT}$ cell migration without affecting ROS level (Figure 5), (iii) several different inhibitors could abolish the HaCaT cell migration (Supplemental Data Figure S1). These data strongly argues that several different downstream signaling pathways are in- 
A

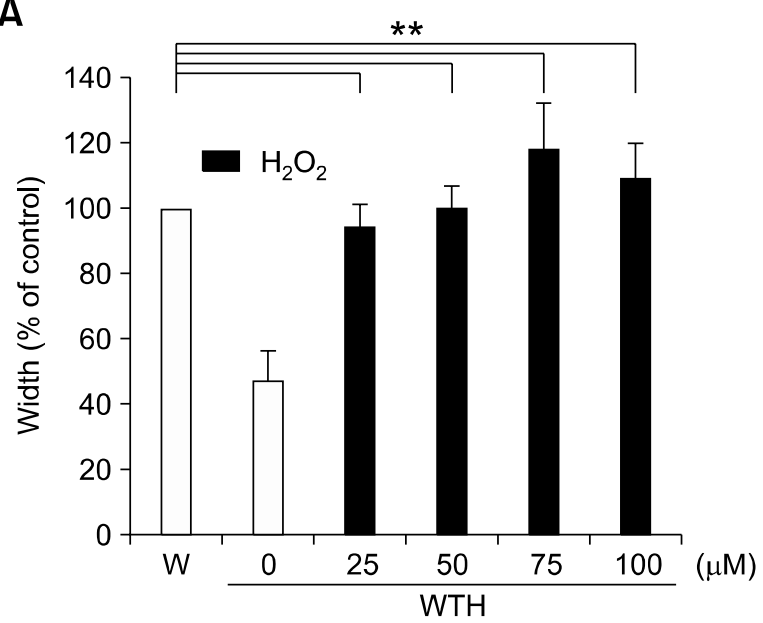

B

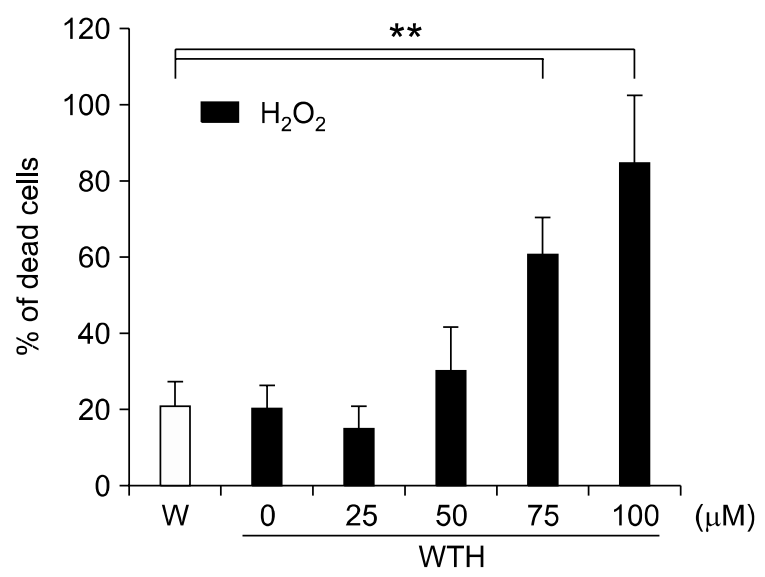

Figure 6. HaCaT cell migration was not enhanced by $\mathrm{H}_{2} \mathrm{O}_{2}$ treatment. HaCaT cells were scratched and different concentrations of $\mathrm{H}_{2} \mathrm{O}_{2}$ were added as indicated. After incubation for $24 \mathrm{~h}$, the respective wells were stained with crystal violet to measure the wound closure (A) or cells were harvested and stained by tryphan blue to measure the cell death (B). Data are presented as mean \pm SD of two independent experiments ${ }^{* *}: P<0.01$ compared to that with cytokine treatment by Student's $t$-test).

volved in keratinocyte migration.

Another well-documented mechanism of enhanced keratinocyte migration other than ROS generation is the secretion of EGF family ligands such as EGF, TGF- $\alpha$, amphiregulin, and HB-EGF, which leads to the autocrine activation of EGFR (Coffey et al., 1987; Cook et al., 1991; Higashiyama et al., 1991). Interestingly, Ellis et al. (2001) showed that scrape-wounding epithelial cell monolayers induce HB-EGF mRNA expression by a mechanism that most probably require Erk-1 and -2 activation, leading to the migration of the cells via activation of EGFR (Ellis et al., 2001). Notably, phosphorylation of both Erk-1 and -2 was significantly increased and sustained by treatment with a combination of both growth factors in our system, and signal inhibitors such as PD98059 and U0126 showed dose-dependent inhibition of $\mathrm{HaCaT}$ cell migration without any significant effect on cell proliferation (unpublished observation by Nam). However, we could not observe the activation of EGFR in our system (Supplemental Data Figure S3).

Re-epithelialization by proliferation and migration of keratinocytes from the margin is one of the principal steps in the complex process of wound healing. Thus, enhancement of re-epithelialization would be beneficial in wound healing process. We have shown in the present study that co-treatment of wounded HaCaT cells with HGF and TGF- $\beta 1$ enhanced keratinocyte migration. Since the use of growth factors as a therapeutic measure to enhance wound healing process appears to be a promising approach, it would be very interesting to test whether combined growth factor treatment would also be beneficial for wound healing in vivo.

\section{Methods}

\section{Cell culture}

The spontaneously immortalized human keratinocyte cell line HaCaT cells (a kind gift from Dr. HY Kang at the Department of Dermatology, Ajou University School of Medicine, Suwon, Korea) were grown in RPMI-1640 medium (Gibco Life Technologies, Rockville, MD) supplemented with $10 \%$ (v/v) heat-inactivated FBS (Gibco) at $5 \% \mathrm{CO}_{2}$ in a humidified atmosphere at $37^{\circ} \mathrm{C}$.

\section{Chemicals}

Recombinant human hepatocyte growth factor (rhHGF) was generously provided by Dr. G. VandeWoude (Laboratory of Molecular Oncology, Van Andel Research Institute, Grand Rapids, MI). HGF concentrations are presented as scatter units $/ \mathrm{ml}$; and 5 units are equivalent to approximately $1 \mathrm{ng}$ of the protein. Recombinant TGF- $\beta 1$ was purchased from R\&D systems (Minneapolis, MN). 2', 7'-dichlorofluorescein diacetate (DCF-DA) was purchased from Molecular Probe Corp. (Eugene, OR Diphenyliodonium and $\mathrm{N}$-acetylcyteine were from Sigma-Aldrich (St Louis, MO). FBS, trypsin-EDTA, and antibiotic-antimycotic containing penicillin $G$ sodium were obtained from Gibco BRL. Protease inhibitor cocktail tablet was purchased from Roche Applied Science (Mannheim, Germany). Phosphatase inhibitors and other reagents, unless specified, were from Sigma Chemical Co.

\section{Scratch wound motility assay}

HaCaT cells were seeded $\left(3 \times 10^{5}\right.$ cells/well) into 24 -well 
plates in RPMI-1640 supplemented with 10\% FBS and allowed to adhere overnight. Cells were then starved with $0.5 \%$ FBS containing media. The mono-layers were then carefully scratched with sterile blue pipette tips and incubated with $0.5 \%$ serum-containing medium with HGF (30 units $/ \mathrm{ml})$ and/or TGF- $\beta 1$ ( $2 \mathrm{ng} / \mathrm{ml})$. After $36 \mathrm{~h}$, cells were washed three times with cold PBS, and then fixed in acetone: methanol $(1: 1, \mathrm{v} / \mathrm{v})$ for $15 \mathrm{~min}$ on ice and stained with $2 \%(w / v)$ crystal violet. The width of the wound was measured by using ocular lens with ruler.

\section{Cell proliferation assay}

To examine the effect of HGF (30 unit/ml) and TGF- $\beta$. (2 $\mathrm{ng} / \mathrm{ml}$ ) on cell proliferation, MTT assay was performed with Cell Proliferation Kit I [MTT; 3-(4,5-dimethylthiazol-2-yl)-2, 5-diphenyl tetrazolium bromide] by following the manufacturer's instruction (Roche Applied Science, Germany).

\section{Migration assay}

HaCaT cells were seeded $\left(1 \times 10^{4}\right.$ cells/well $)$ into 24 -well plates in RPMI- 1640 containing $0.1 \%$ FBS onto the microporuos membrane $(8.0 \mu \mathrm{m})$ in the upper chamber of the Transwell $^{\circledR}$ (Corning, NY). Twenty-Four $h$ after the treatment with cytokines, the unmigrated cells in the upper chamber were gently removed by using a cotton swab. Cells which had migrated through the membrane to the lower chamber were fixed, stained with crystal violet and washed. Migration was determined by counting the cells on the lower surface of the filter by phase-contrast microscopy at $\times 100$ magnification.

\section{Inhibitor study}

Wounded $\mathrm{HaCaT}$ cells were pre-treated for $30 \mathrm{~min}$ with various inhibitors of cell signaling. After then, both HGF (30 units $/ \mathrm{ml})$ and TGF- $\beta 1(2 \mathrm{ng} / \mathrm{ml})$ were added to the cells for $30 \mathrm{~h}$ along with indicated inhibitors. After staining with crystal violet, width of the wound was measured by using ocular lens with ruler.

\section{Intracellular $\mathrm{H}_{2} \mathrm{O}_{2}$ concentration}

$\mathrm{HaCaT}$ cells were seeded in $60 \mathrm{~mm}$-petri dishes. After 24 $h$, culture media were changed with fresh RPMI- 1640 media containing $0.5 \%$ FBS. After another $24 \mathrm{~h}$, confluent cells were scratched using a comb and cytokines were added as indicated. After incubating for $30 \mathrm{~min}$ or $20 \mathrm{~h}$, cells were washed with PBS and incubated for $10 \mathrm{~min}$ in the dark at $37^{\circ} \mathrm{C}$ with the same solution containing $8 \mu \mathrm{M} 2^{\prime}$, 7'-dichlorofluorescein diacetate (DCF-DA; Molecular Probes). DCF-DA is oxidized by $\mathrm{H}_{2} \mathrm{O}_{2}$ to highly fluorescent 2', 7'-dichlorofluorescein (DCF). The cells were then examined with a laser scanning confocal microscope (model Fluoview 300; Olympus) equipped with an argon laser tuned to an excitation wavelength of $488 \mathrm{~nm}$, and a Olympus $\times 100$ objective lens. For determination of intracellular ROS level by FACS, we prepared cells in the same manner. Stained cells were washed, re-suspended in PBS, and analyzed by flow cytometry (FACS Vantage,
Becton Dickinson Corp.).

\section{Transfection of shRNAs for Nox-1 and Nox-4}

ShRNA constructs specific for Nox-1 or Nox-4 were generous gifts from Dr. YS Bae (Ewha Womans University, Seoul, Korea), and were generated as previously described (Park et al., 2004). Briefly, specific sequences of 19 nucleotides of human Nox-1 (CCAGGATTGAAGTGGATGG, residues 1130 to 1148) and Nox-4 cDNA (GTCAACATCCAGCTGTACC, residues 1474 to 1492) were used for the synthesis of small interfering RNAs (siRNAs). The pSUPER vector for shRNAs was purchased from Oligoengine. The phosphorylated oligonucleotides were annealed and cloned into the pSUPER vector by the use of Bglll ( 5 ' end) and HindlII ( 3 ' end). Cells were transfected by electroporation.

\section{Electroporation of HaCaT cells}

Electroporation (Amaxa Biosystems, Cologne, Germany) was performed as described previously (Lenz et al., 2003). HaCaT cells $\left(3 \times 10^{5}\right)$ were centrifugated, and the pellet was then resuspended in RPMI-1640 media containing $10 \%$ FBS. Plasmid DNAs $(7 \mu \mathrm{g})$ were mixed with $250 \mu \mathrm{l}$ of cell suspension, transferred into $4.0 \mathrm{~mm}$-wide ELECTROPORATION CUVETTES PLUS ${ }^{\text {TM }}$ (A Division of Genetronics, USA), and electroporated with an Amaxa Nucleofector apparatus, using an appropriate program supplied by the manufacturer. After electroporation, the cells were immediately transferred to complete medium and cultured in $60-\mathrm{mm}$ culture dishes at $37^{\circ} \mathrm{C}$ until analysis.

\section{Supplemental data}

Supplemental Data include three figures and can be found with this article online at http://e-emm.or.kr/article/article files/SP-42-4-03.pdf.

\section{Acknowledgments}

We thank Dr. Woon-Ki Paik for his review of this manuscript; Dr. YS Bae for shRNA constructs, Dr. HY Kang for HaCaT human keratinocyte cells, and Dr. GF VandeWoude for recombinant human HGF. This work was supported by Grant No. R13-2003-019 from the Korea Science and Engineering Foundation through Chronic Inflammatory Disease Research Center.

\section{References}

Ago $T$, Nunoi $H$, Ito $T$, Sumimoto $H$. Mechanism for phosphorylation-induced activation of the phagocyte NADPH oxidase protein p47(phox). Triple replacement of serines 303,304 , and 328 with aspartates disrupts the $\mathrm{SH} 3$ domain-mediated intramolecular interaction in p47(phox), thereby activating the oxidase. J Biol Chem 1999;274: 33644-53

Babior BM. NADPH oxidase: an update. Blood 1999;93: 1464-76 
Bae YS, Kang SW, Seo MS, Baines IC, Tekle E, Chock PB, Rhee SG. Epidermal growth factor (EGF)-induced generation of hydrogen peroxide. Role in EGF receptor-mediated tyrosine phosphorylation. J Biol Chem 1997;272:217-21

Bae YS, Sung JY, Kim OS, Kim YJ, Hur KC, Kazlauskas A, Rhee SG. Platelet-derived growth factor-induced $\mathrm{H}(2) \mathrm{O}(2)$ production requires the activation of phosphatidylinositol 3-kinase. J Biol Chem 2000;275:10527-31

Brar SS, Kennedy TP, Sturrock AB, Huecksteadt TP, Quinn MT, Whorton AR, Hoidal JR. An NAD(P)H oxidase regulates growth and transcription in melanoma cells. Am J Physiol Cell Physiol 2002;282:C1212-24

Carter K. Growth factors: the wound healing therapy of the future? Br J Community Nurs 2003;8:S15-23

Chamulitrat W, Stremmel W, Kawahara T, Rokutan K, Fujii $\mathrm{H}$, Wingler K, Schmidt HH, Schmidt R. A constitutive NADPH oxidase-like system containing gp91phox homologs in human keratinocytes. J Invest Dermatol 2004;122:1000-9

Cheng G, Cao Z, Xu X, van Meir EG, Lambeth JD. Homologs of gp91phox: cloning and tissue expression of Nox3, Nox4, and Nox5. Gene 2001;269:131-40

Coffey RJ Jr, Derynck R, Wilcox JN, Bringman TS, Goustin AS, Moses HL, Pittelkow MR. Production and auto-induction of transforming growth factor-alpha in human keratinocytes. Nature 1987;328:817-20

Conway K, Price P, Harding KG, Jiang WG. The molecular and clinical impact of hepatocyte growth factor, its receptor, activators, and inhibitors in wound healing. Wound Repair Regen 2006;14:2-10

Cook PW, Mattox PA, Keeble WW, Pittelkow MR, Plowman GD, Shoyab M, Adelman JP, Shipley GD. A heparin sulfate-regulated human keratinocyte autocrine factor is similar or identical to amphiregulin. Mol Cell Biol 1991;11: 2547-57

Cross AR, Erickson RW, Curnutte JT. The mechanism of activation of NADPH oxidase in the cell-free system: the activation process is primarily catalytic and not through the formation of a stoichiometric complex. Biochem J 1999;341 (Pt 2):251-5

Ellis PD, Hadfield KM, Pascall JC, Brown KD. Heparinbinding epidermal-growth-factor-like growth factor gene expression is induced by scrape-wounding epithelial cell monolayers: involvement of mitogen-activated protein kinase cascades. Biochem J 2001;354:99-106

Finkel T. Oxygen radicals and signaling. Curr Opin Cell Biol 1998;10:248-53

Finkel T. Redox-dependent signal transduction. FEBS Lett 2000;476:52-4

Finkel T, Holbrook NJ. Oxidants, oxidative stress and the biology of ageing. Nature 2000;408:239-47

Gamaley IA, Klyubin IV. Roles of reactive oxygen species: signaling and regulation of cellular functions. Int Rev Cytol
1999;188:203-55

Higashiyama S, Abraham JA, Miller J, Fiddes JC, Klagsbrun M. A heparin-binding growthfactor secreted by macrophagelike cells that is related to EGF. Science 1991;251:936-9

Kingsley DM. The TGF-beta superfamily: new members, new receptors, and new genetic tests of function in different organisms. Genes Dev 1994;8:133-46

Lambeth JD, Cheng G, Arnold RS, Edens WA. Novel homologs of gp91phox. Trends Biochem Sci 2000;25:45961

Lassegue B, Sorescu D, Szocs K, Yin Q, Akers M, Zhang Y, Grant SL, Lambeth JD, Griendling KK. Novel gp91(phox) homologues in vascular smooth muscle cells : nox1mediates angiotensin II induced superoxide formation and redoxsensitive signaling pathways. Circ Res 2001;88:888-94

Lenz P, Bacot SM, Frazier-Jessen MR, Feldman GM. Nucleoporation of dendritic cells:efficient gene transfer by electroporation into human monocyte-derived dendritic cells. FEBS Lett 2003;538:149-54

Logan DC. The mitochondrial compartment. J Exp Bot 2006;57:1225-43

Park HS, Lee SH, Park D, Lee JS, Ryu SH, Lee WJ, Rhee SG, Bae YS. Sequential activation of phosphatidylinositol 3-kinase, beta Pix, Rac1, and Nox1 in growth factor-induced production of H2O2. Mol Cell Biol 2004;24:4384-94

Park HS, Chun JN, Jung HY, Choi C, Bae YS. Role of NADPH oxidase 4 in lipopolysaccharide induced proinflammatory responses by human aortic endothelial cells. Cardiovasc Res 2006;72:447-55

Robinson CJ. Growth factors: therapeutic advances in wound healing. Ann Med 1993;25:535-8

Singer AJ, Clark RA. Cutaneous wound healing. N Engl J Med 1999;341:738-46

Steed DL. Modifying the wound healing response with exogenous growth factors. Clin Plast Surg 1998;25:397-405

Sundaresan M, Yu ZX, Ferrans VJ, Irani K, Finkel T. Requirement for generation of $\mathrm{H} 2 \mathrm{O} 2$ for platelet-derived growth factor signal transduction. Science 1995;270:296-9

Taipale J, Saharinen J, Keski-Oja J. Extracellular matrix-associated transforming growth factor beta: role in cancer cell growth and invasion. Adv Cancer Res 1998; 75:87-134

Wang XJ, Han G, Owens P, Siddiqui Y, Li AG. Role of TGF beta-mediated inflammation in cutaneous wound healing. The journal of investigative dermatology Symposium proceedingst he Society for Investigative Dermatology, Inc 2006;11:112-7

Zarnegar R, Michalopoulos GK. The many faces of hepatocyte growth factor: from hepatopoiesis to hematopoiesis. J Cell Biol 1995;129:1177-80 